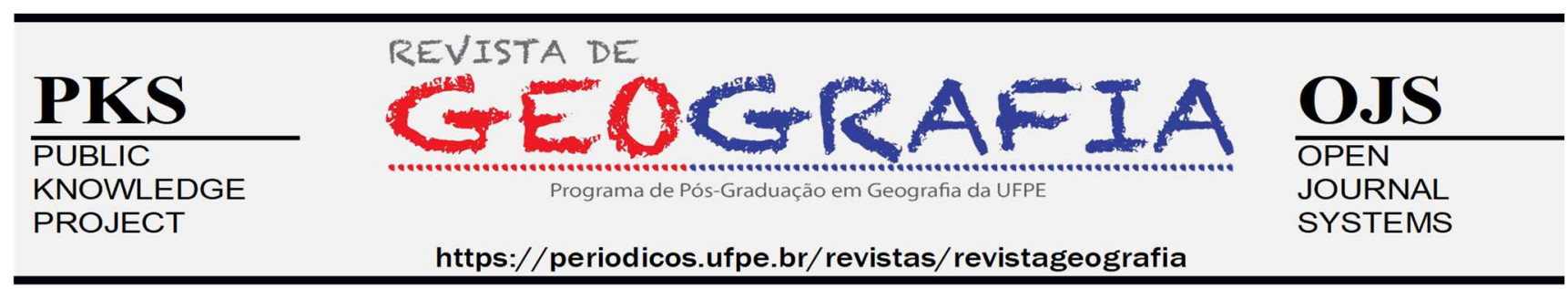

\title{
MUNICÍPIOS LITORÂNEOS DO PIAUÍ E PRODUÇÃO DO ESPAÇO TURÍSTICO
}

\author{
Jorge Martins Filho ${ }^{1}$
}

\begin{abstract}
${ }^{1}$ Docente Adjunto da Universidade Estadual do Piauí - UESPI, Centro de Ciências Humanas e Letras - CCHL - Campus Poeta Torquato Neto - Teresina (PI) e Universidade Estadual do Maranhão - UEMA, Centro de Estudos Superiores de Caxias - Caxias (MA). E-mail: jmartinsf@gmail.com; http://orcid.org/0000-0003-1174-2010
\end{abstract}

Artigo recebido em 01/06/2020 e aceito em 26/02/2021

\begin{abstract}
RESUMO
A aceleração das transformações de caráter territorial decorrentes do Turismo em certos pontos do litoral do Nordeste brasileiro tem produzido novas formas de produção do espaço geográfico, com amplas repercussões socioeconômicas, políticas e culturais, que devem ser objeto de preocupação dos agentes responsáveis pelo planejamento e gestão do Turismo. Este artigo resulta de uma reflexão sobre caminhos, seguidos pelos órgãos público e privado, enquanto agentes do Turismo, responsáveis pelo desenvolvimento de projetos nos municípios do litoral piauiense, e que devem agir com base em ações que dinamizem (e privilegiem) os interesses locais; direcione projetos para romper os fatores que limitam a inserção do litoral piauiense no mercado do Turismo nacional e internacional, com a dinamização dos fluxos; criação de novas conectividades e melhoria da infraestrutura. A pesquisa foi desenvolvida a partir do uso de fotografias e dados estatísticos encontrados na base de dados do Instituto Brasileiro de Geografia e Estatística (IBGE), do Programa das Nações Unidas para o Desenvolvimento (PNUD), entre outros. Constatamos, ao final, que o aprimoramento da infraestrutura do litoral piauiense é fator primordial não somente para o desenvolvimento da atividade turística, mas também para a melhoria da qualidade de vida da população local.
\end{abstract}

Palavras-chave: Turismo. Fluxo turístico. Infraestrutura turística. Piauí.

\section{COASTAL MUNICIPALITIES OF PIAUÍ AND PRODUCTION OF TOURIST SPACE}

\begin{abstract}
The acceleration of territorial transformations resulting from tourism in certain points of the Brazilian northeast coast has produced new forms of production of the geographical space, with wide socioeconomic, political and cultural repercussions, which should be the object of the concern of the agents responsible for tourism planning and management. This article is the result of a reflection on the paths followed by public institutions and private bodies, as tourism agents, responsible for the development of projects in the municipalities of Piaui coast and that must act based on actions that energize (and privilege) local interests; direct projects to break the factors that limit the insertion of Piaui coast in the national and international tourism market, with the promotion of flows; the creation of new connectivity and infrastructure improving. The research was developed through the use of photographs and statistical data found in the database of the Brazilian Institute of Geography and Statistics (IBGE) and the United Nations Development Program (UNDP), among others. It could be found that the improvement of Piaui coast infrastructure is a fundamental factor not only for the development of the tourism activity but also for the improvement of the local population quality of life.
\end{abstract}

Keywords: Tourism. Tourist flow. Tourist infrastructure. Piauí. 


\title{
MUNICIPIOS COSTEROS DE PIAUÍ Y PRODUCCIÓN DEL ESPACIO TURÍSTICO
}

\begin{abstract}
RESUMEN
La aceleración de los cambios de carácter territorial provenientes del Turismo en ciertos puntos del litoral del Noreste brasileño ha producido nuevas formas de producción del espacio geográfico, con amplias repercusiones socioeconómicas, políticas y culturales, que deben ser motivo de preocupación de los agentes responsables por la planificación y gestión del Turismo. Este artículo resulta de una reflexión sobre caminos seguidos por los órganos públicos y privados en la condición de agentes del Turismo, responsables por el desarrollo de proyectos en los municipios del litoral piauiense, y que deben actuar con base en acciones que dinamicen (y privilegien) los intereses locales. Además, deben apuntar proyectos parar romper los factores que limitan la inserción del litoral piauiense en el mercado del Turismo nacional e internacional, con la dinamización de los flujos, creación de nuevas conectividades y mejoría de la infraestructura. La investigación fue desarrollada a partir del uso de fotografías y datos estadísticos encontrados en la base de datos del Instituto Brasileño de Geografía y Estadística (IBGE), del Programa de las Naciones Unidas para el Desarrollo (PNUD), entre otros. Constatamos, al final, que el perfeccionamiento de la infraestructura del litoral piauiense es factor primordial no solamente para el desarrollo de la actividad turística, pero también para la mejoría de la calidad de vida de la población local.
\end{abstract}

Palabras clave: Turismo. Flujo turístico. Infraestructura turística. Piauí.

\section{INTRODUÇÃO}

O fenômeno turístico tem a capacidade de produzir o espaço geográfico, possibilitando aos geógrafos interesse em analisar e interpretar a dinâmica espacial, para compreender sua estruturação e os processos que o engendram. O Nordeste brasileiro constitui um dos principais destinos turísticos do País, principalmente na sua porção litorânea, na qual ainda existem espaços com potencialidades de ampliar a participação da região no contexto do turismo nacional e internacional.

Entre os lugares que sofrem intervenções no sentido de maximizar o seu potencial turístico, encontram-se os municípios que ocupam o litoral do Estado do Piaú. Esses municípios aparecem como exemplo de uma valorização que envolve Estado, agentes econômicos, turistas e população local. Alguns espaços são reordenados a partir de uma funcionalidade comandada pelo Turismo. Implantam-se novos equipamentos e infraestruturas, voltados a atender à demanda turística. O Delta do Parnaíba, por exemplo, e a costa litorânea podem ser apontados como um dos principais atrativos turísticos do Piauí (PERINOTTO, 2013).

Por sua vez, o estabelecimento de equipamentos em vários pontos de atração fixa a atividade e promove roteiros, associando as estratégias de divulgação das regiões vizinhas, que investiram na atividade turística. Deste modo, o litoral do Piauí integra o consórcio "Rota das Emoções" (BRASIL, 2014), composto por municípios dos Estados do Maranhão, Piauí e Ceará, que objetiva explorar as 
potencialidades turísticas do litoral desses Estados. Conforme Bouças da Silva e Ribeiro (2018), este é considerado o primeiro consórcio interestadual em Turismo do Brasil.

Logo, com a introdução da atividade turística, estaríamos diante de um vetor de reorganização produtiva do espaço que envolve a administração pública e o setor privado, responsáveis pela seleção desses espaços, promoção de atividades e investimentos em infraestrutura e equipamentos turísticos que constituem a base material da dinâmica e das relações espaciais vinculadas ao desenvolvimento do Turismo.

Convém assinalar que o propósito deste artigo é compreender as transformações do espaço litorâneo do Estado do Piauí em função da introdução e desenvolvimento dos serviços ligados ao Turismo.

Essa pesquisa foi desenvolvida a partir da utilização de fotografias selecionadas para demonstrar a dinâmica social do fenômeno turístico nas cidades do litoral piauiense. Para tanto, fezse uso de indicadores encontrados nas bases de dados existentes no Instituto Brasileiro de Geografia e Estatística (IBGE), no Programa das Nações Unidas para o Desenvolvimento (PNUD) dentre outros.

O conjunto desses indicadores constituiu uma primeira tentativa de categorizar os espaços turísticos do litoral do Piauí, considerando-se as instituições e órgãos de governo, bem como a população residente na área.

\section{O LITORAL DO PIAUÍ NO CONTEXTO DO TURISMO}

Segundo Baptista (2010), a zona costeira do Piauí compreende aproximadamente $1.200 \mathrm{~km}^{2}$,

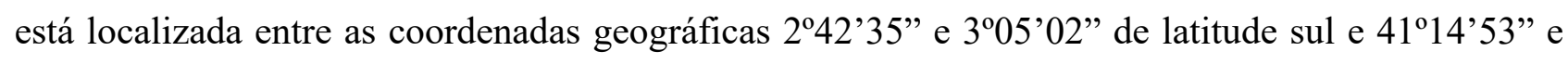
$41^{\circ} 52$ '46" de longitude oeste, apresenta como divisa a leste o Estado do Ceará e a oeste o Estado do Maranhão, com uma extensão linear de $66 \mathrm{~km}$. Fazem parte desta os municípios de Cajueiro da Praia, Ilha Grande, Luís Correia e Parnaíba, que podem ser acessados a partir de Teresina, Fortaleza e São Luís, pelas rodovias BR 343, BR 222 e BR 402 respectivamente.

Por outro lado, o Plano Estratégico de Desenvolvimento do Turismo no Piauí, elaborado pelo Serviço de Apoio às Micro e Pequenas Empresas do Piauí/SEBRAE-PI (2012), considera a existência do Polo Costa do Delta, em razão de este abranger os municípios de Buriti dos Lopes, Cajueiro da Praia, Ilha Grande, Luís Correia e Parnaíba. Tendo como segmentos atuais o ecoturismo, sol e praia, turismo de aventura e turismo esportivo. Contudo, saliente-se que, para efeito deste trabalho, será 
excluído o município de Buriti dos Lopes pelo fato de não compor os municípios da faixa litorânea do Piauí (Figura 1).

\section{FIGURA 1 - MUNICÍPIOS LITORÂNEOS DO PIAUÍ}

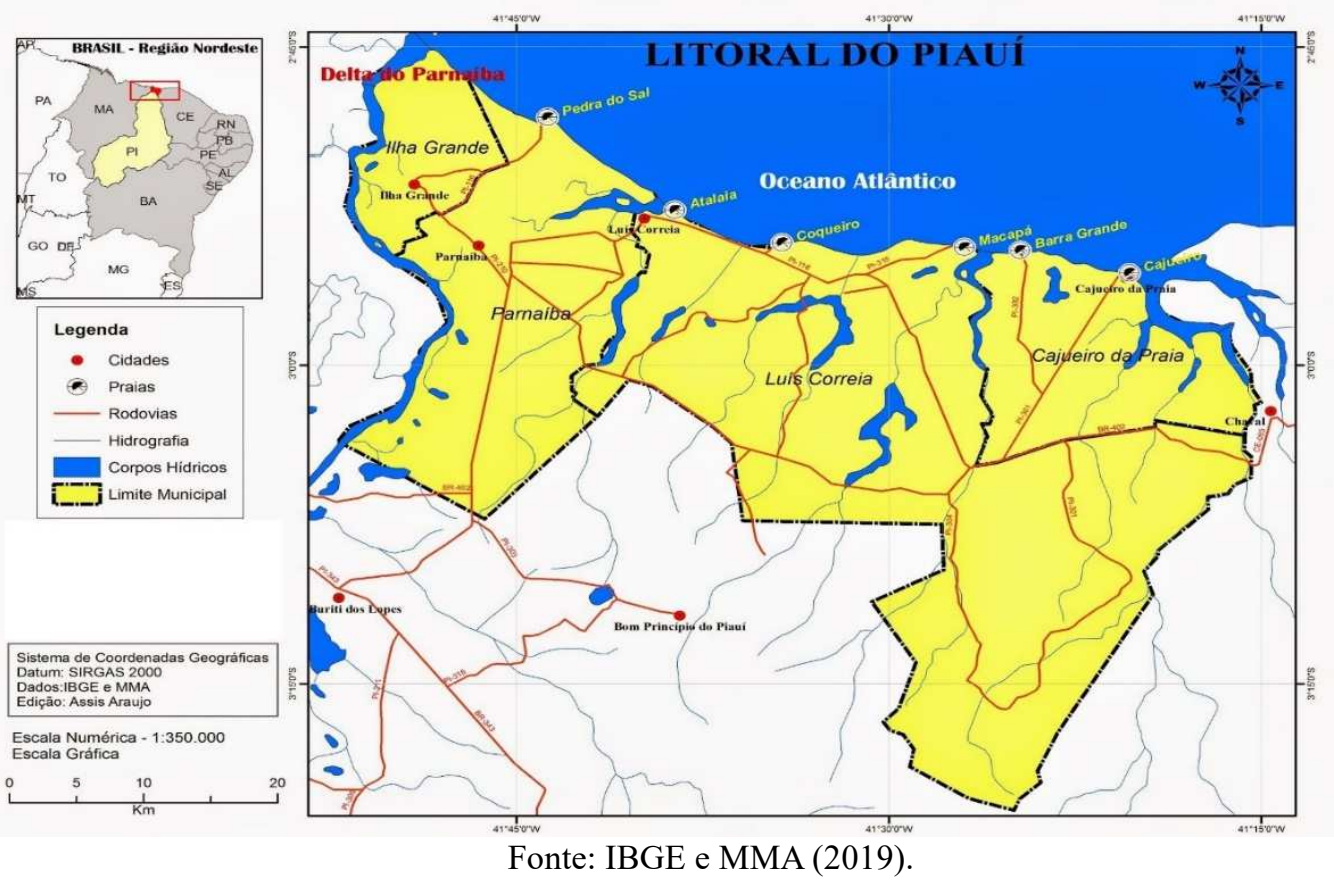

Os municípios litorâneos contam com uma população estimada em 200.457 habitantes (IBGE, 2019). Parnaíba, com seus 153.078 habitantes, é certamente o município que tem mais infraestrutura de serviços. Luís Correia aparece com 30.311 habitantes e se destaca como cidade em que grande parte da população é flutuante. Ilha Grande, com 9.426, e Cajueiro da Praia, com 7.642 habitantes, foram criados recentemente e necessitam, ainda mais, de investimentos para a consolidação de infraestrutura.

O MTur (2012) considera que no Estado do Piauí existem três destinos indutores, os quais apresentam características de núcleo receptor e/ou distribuidor de fluxos turísticos, que mostram forte capacidade de dinamizar a economia do espaço em que estão inseridos. São eles Teresina (Polo Teresina) - capital do Estado, Parnaíba (Polo Costa do Delta) e São Raimundo Nonato (Polo das Origens).

Quanto ao aprimoramento da conectividade nacional, o incremento de voos comerciais de passageiros e o aprimoramento da infraestrutura aeroportuária foram responsáveis pelo aumento de 
turistas que buscam locais em que possam desfrutar a riqueza paisagística e cultural da região Nordeste.

Esse aumento no fluxo de turistas poderia beneficiar o litoral do Piauí, causando nova demanda, todavia, essa demanda não tem gerado fluxo de turistas suficiente para que as cidades se posicionem em um patamar de destaque, frente às demais cidades litorâneas da região Nordeste.

O litoral piauiense apresenta, como motivação específica para viagem, um percentual de 70,08\% voltado para o Turismo de Sol e Praia, segundo dados do SEBRAE/PI (2012).

Com todo o potencial existente e a possibilidade de desenvolvimento das estruturas turísticas, é possível atingir os benefícios econômicos. Contudo, é preciso ressaltar a possibilidade da repercussão de determinados impactos negativos decorrentes da falta de ordenamento territorial.

A adoção de estratégias se faz necessária, para corrigir os problemas de infraestrutura e de adequação da oferta de equipamentos e serviços turísticos à demanda, ordenando o desenvolvimento do Turismo de Sol e Praia. Acrescente-se que o crescimento e o desenvolvimento da área ainda são incapazes de sustentação exclusiva na atividade turística, o que exige considerar as demais atividades existentes na região e a criação de ações voltadas ao aumento da produtividade e agregação de valor.

Além disso, devem ser criadas outras estratégias que busquem no Ecoturismo e no Turismo de Aventura impactos positivos para as comunidades que os desenvolvem, como benefício econômico, valor agregado e melhor manejo das áreas protegidas, desenvolvimento de atividades educativas e científicas, e, ainda, a conservação da biodiversidade.

A inserção do litoral piauiense no Consórcio Rota das Emoções promoveu o processo de ligação entre seus municípios e o seu entorno e desencadeou novas expectativas de especulações imobiliárias, e expansão do comércio; enfim, reforçou uma territorialidade cada vez mais relacionada ao Turismo.

Por conseguinte, rompido o relativo isolamento geográfico e em razão do aumento da valorização das belezas naturais, as cidades do litoral piauiense iniciaram um processo de intensas transformações. 


\section{A VALORIZAÇÃO DOS LUGARES COMO ATRATIVO TURÍSTICO}

A valorização dos espaços turísticos do litoral do Piauí associa-se à manutenção dos valores naturais e sociais. No entanto, observou-se, com bastante clareza, que o litoral experimenta agravamento das disparidades socioespaciais com a consequente fragmentação articulada dos espaços turísticos. Parte das disparidades espaciais detectadas é resultado de "padronização" de ações desenvolvidas nas mais diferentes escalas, com o objetivo de atender à necessidade da atividade turística.

As cidades do litoral piauiense precisam desenvolver a valorização das identidades, mesmo que se entenda o espaço dessas cidades como aquele conferido por seu uso. Ou seja, a maneira como o ser humano se apropria para produzir a vida, o que significa a cidade como o lugar da formação da identidade e da memória (CARLOS, 2004).

Neste contexto, o lugar é definido pela influência acumulada por meio do tempo histórico, seja do passado seja das relações das forças presentes. A representação da sociedade é realizada por seu patrimônio, no qual se encontram a ideologia, cultura, organizações, instituições, religião e território, todos resultados das forças ativas dos membros que compõem o lugar. Para o desenvolvimento do Turismo, é essencial que esse patrimônio seja preservado e respeitado.

Ao referir-se ao Turismo como fonte de "espetáculo", Carlos (2007) corrobora a ideia de que os lugares são marcados por ritmos diversos, novas relações pessoais, criação de novos símbolos ou substituição destes por sinais, que passam a ganhar novo conteúdo cujo papel principal é redefinir os antigos lugares e, em consequência, criar novos. O lugar, como experiência humana, possibilita a todos o despertar das afeições e obrigações, posto que se passa a conhecer o mundo mediante aqueles lugares onde se vive.

Quando os lugares são ocupados por objetos que lhes são estranhos, em face da atividade do Turismo, cuja lógica, por vezes, não leva em consideração a história e a cultura, introduz elementos que não são apropriados ao lugar (CRUZ, 2000). A paisagem urbana passa, então, a perder os aspectos históricos de suas conquistas. Trata-se do caminhar de um processo que desconfigura o espaço do passado e cria condições de explorações a partir das novas utilidades. 
A representação da cidade e de suas paisagens é posta em risco; o imaginário coletivo da cidade configura-se em um processo secundário de percepção, substituído pelo "novo" modelo de interpretação do urbano.

A cidade, em cada época, representa a base material e subjetiva da história e da sociedade por meio dos instrumentos duráveis. Os centros das cidades brasileiras retratam em grande parte a permanência, uma espécie de herança, dos processos de produção do espaço histórico. O Turismo, na maioria das vezes, apropria-se dessas heranças de forma perversa, com o objetivo de deflagrar novo modo de uso desses espaços.

Surge a dialética entre a manutenção e a transformação dos edifícios históricos, de forma simbólica ou material, a validação de seu testemunho ocorre pelas constantes transformações ou adaptações aos novos tempos.

Para Santos (2012, p. 46), “[...] o meio urbano é cada vez mais um meio artificial, fabricado com restos da natureza primitiva, crescentemente encobertos pelas obras dos homens". Os monumentos têm significados próprios para esta ou aquela cidade, por contribuírem para as referências relativas ao conjunto de ações sociais do passado, e remeterem a leituras novas de antigas formas construídas.

Assinale-se que as transformações ocorridas no espaço estão ligadas aos interesses do capital e podem tornar o homem estranho ao seu lugar. O planejamento do Turismo deve evitar, pois, tais ocorrências, confrontando o poder do dinheiro de transformar o espaço em benefício de sua produção ampliada.

Para Santos (1997), a produção do espaço padronizado cria um produto em que objetos que o compõem são utilizados da melhor forma pelos atores hegemônicos. Para responder às necessidades imperativas do mercado, pode-se observar que os espaços apropriados pelo consumo turístico vêm sofrendo uma reprodução que corresponde aos interesses, quase sempre, de agentes exógenos. Em sua concepção, o comportamento das formas deve ser mantido, mas em novas situações. A história poderia atribuir funções diferentes ao mesmo lugar, funções que se sobrepõem.

O lugar possui uma autonomia de existência, mas não possui uma autonomia de significação, pois "todos os dias novas funções substituem as antigas, novas funções se impõem e se exercem" (SANTOS, 2012, p. 59). Este é o caso das cidades que, em razão do Turismo, passam a ter novas funções. Tornam-se cidades de consumo, com o descaso pelo conteúdo local, ou seja, memorial 
significativo. Os valores dos bens culturais são encontrados nas formas e além delas; podem ser percebidos na integração do espaço da vida presente com a continuidade histórica do lugar.

Por outro lado, relacionadas a essas reflexões, pode-se constatar que as "rugosidades" apresentadas pelas cidades do litoral piauiense, em especial na área central de Parnaíba (Figura 2), refletem as transformações espaciais decorrentes dos diferentes processos produtivos que se inseriram no espaço urbano. Além dos valores materializados na rica arquitetura local, a região apresenta outras formas de utilização dos recursos turísticos, entre eles a grande quantidade de praias adequadas ao banho de mar e às práticas esportivas.

\section{FIGURA 2 - MATERIALIDADE HISTÓRICA DE PARNAÍBA E SUAS RUGOSIDADES: (A) ENTRADA PRINCIPAL DO PORTO DAS BARCAS; (B) VISTA PARCIAL DO PORTO DAS BARCAS}

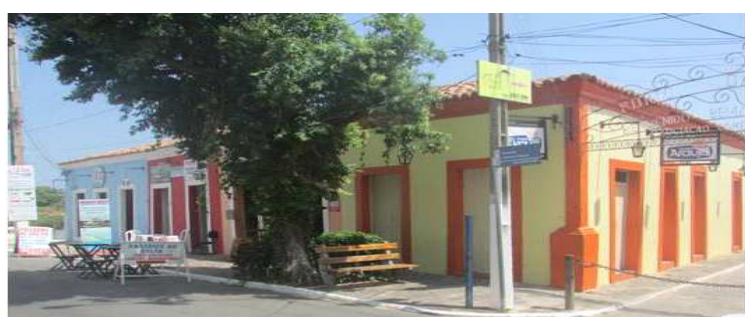

(a)

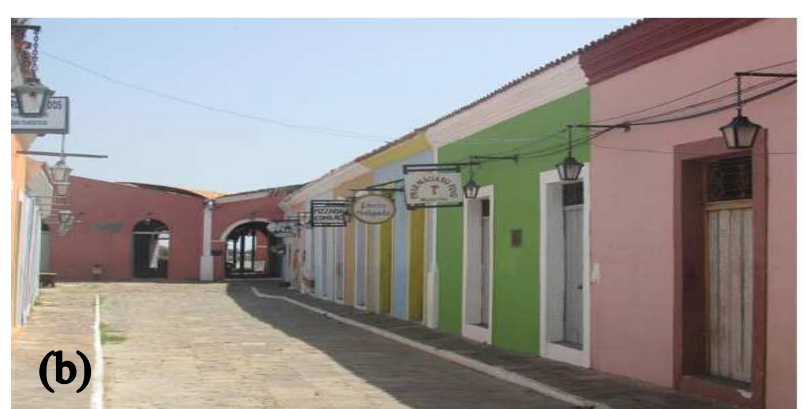

(b)

Fonte: Arquivo do autor (2019).

Porém, não se trata somente das potencialidades naturais e culturais que se destacam na região. O processo de crescimento das duas maiores cidades do litoral piauiense, Parnaíba e Luís Correia, resultou no aumento da precarização da moradia, fazendo surgir loteamentos periféricos como alternativa de habitação da população mais carente.

Nas cidades voltadas para o Turismo, o espaço urbano é apropriado e direcionado funcionalmente para atividades economicamente específicas. Isso cria um cenário de segregação expressado pela urbanização voltada a esta atividade. Neste sentido, o espaço a ser consumido pelo Turismo está ligado a uma organização pontual, com a utilização da imagem e da cultura como temas centrais, assim como a arquitetura que se volta à valorização dos marcos simbólicos.

Portanto, o que temos é um modelo de padronização das paisagens turísticas que valorizam o processo de segregação dos territórios, como forma de manter os turistas confinados, com barreiras visíveis ou não. A tendência surgida a partir da segunda metade do século passado tem sido prática comum em busca de novas formas de lazer e ócio no litoral. Com isso, tornou-se rotineiro o 
deslocamento de uma parcela considerável da população dos centros urbanos em direção ao litoral nos períodos de férias, prolongados feriados, e finais de semana, o que incentiva novas edificações e ou adaptações de moradias temporárias para os mais variados estratos sociais.

Conforme Sousa (2012, p. 146), “o processo de turistificação da zona costeira não só nordestina, mas de todo o litoral brasileiro, se iniciou com o turismo residencial". O surgimento do imobiliário turístico, na forma de meios de hospedagem e segunda residência, podem ser detectados em boa parte do litoral piauiense (Figura 3).

FIGURA 3 - EXEMPLOS DE EMPREENDIMENTOS IMOBILIÁRIOS E OCUPAÇÃO DA ORLA: (A) LOTEAMENTO NA RODOVIA BR 343, KM 09; (B) POUSADA NO MUNICÍPIO DE CAJUEIRO DA PRAIA
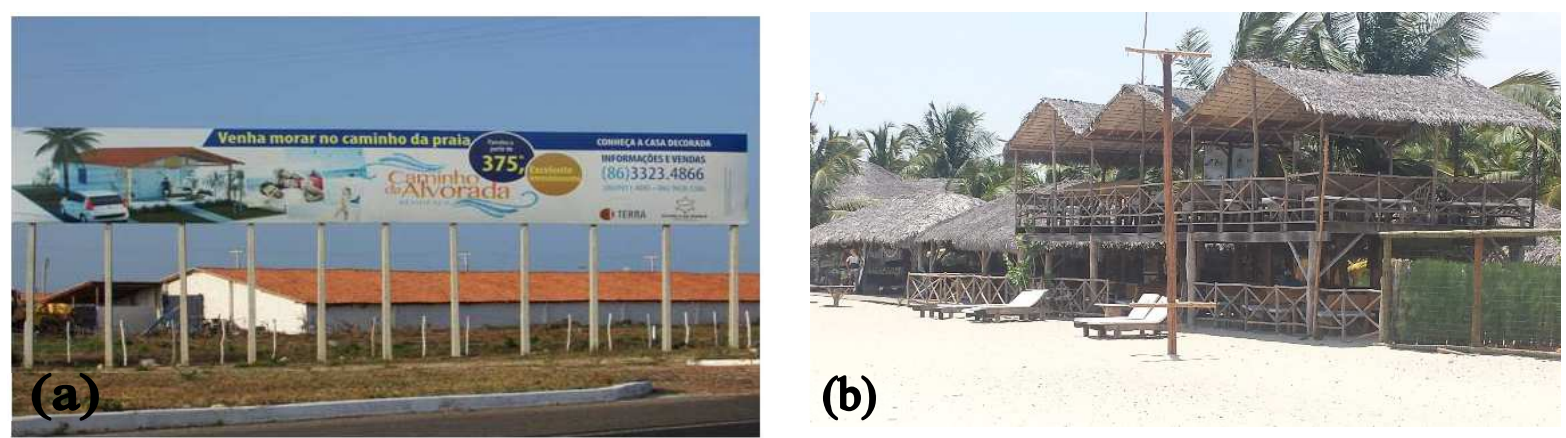

(b)

Fonte: Arquivo do autor (2019).

Parnaíba e Luís Correia na década de 1980, e Cajueiro da Praia, recentemente, iniciaram um processo de produção do espaço urbano, em que o chamado "veraneio", modalidade de turismo em que é utilizada a "segunda residência" como alojamento temporário para o lazer, encontra-se destacado e proporciona o aparecimento de áreas segregadas e loteamentos exclusivos.

Segundo dados do IBGE (2010), a cidade de Luís Correia apresenta o maior percentual de domicílios considerados segunda residência entre os municípios do litoral piauiense. De um total de 10.985 domicílios particulares, 3.065 são considerados domicílios de uso ocasional, um percentual de 27,91\%. Cajueiro da Praia aparece na segunda posição com 10\% de seus domicílios considerados de uso ocasional e Parnaíba logo a seguir com 3,53\%.

A expansão inicial dos domicílios destinados à segunda residência, de caráter espontâneo e sem planejamento, é apontada por Dantas (2009) como um fenômeno que se desenvolve como efeito da moda, e que oferece loteamentos sem nenhuma infraestrutura. E isso se torna dado complicador para a vilegiatura, pois se trata de atividades que necessitam dispor de infraestrutura basilar para utilização de utensílios trazidos da cidade para as zonas de praias. 
A urbanização das áreas turísticas tem ocorrido de modo a obedecer aos comandos da ordem política capitalista, com o objetivo de levar as cidades a se pautarem pelo consumo e pelas ações imediatistas que produzam a aparência do lugar. Desta forma, o procedimento utilizado para a urbanização dos espaços turísticos adota um modelo de ação tópica e abandona definitivamente as ações estruturais em relação ao processo de produção do espaço.

Tendo-se em vista que o Turismo tem um efeito urbanizador, percebe-se que o processo de massificação da era moderna em escala regional demanda grande quantidade de serviços orientados, na maioria dos casos, em direção a um processo de urbanização mal-entendido. Convém salientar que a construção desses empreendimentos imobiliários no litoral piauiense tem provocado o aumento da poluição por esgotos e resíduos sólidos, como também o desmonte parcial ou total de dunas para a construção de habitações, a degradação da paisagem cênica motivada pela eliminação da vegetação original, a comercialização e ocupação de áreas de preservação permanentes, o uso inapropriado dos espaços públicos e conflitos socioculturais entre a população local e os turistas de segunda residência.

$\mathrm{O}$ aumento de segunda residência corresponde claramente a uma forma de assentamento urbano que ocasiona a redução de espaços destinados a outras atividades econômicas, que são próprias dos moradores locais, como agricultura e extrativismo.

\section{OS FLUXOS NA PRODUÇÃO DO ESPAÇO TURÍSTICO}

Os fluxos resultam de movimento de circulação de produtos, informações e pessoas. Eles refletem as interações espaciais procedentes da divisão social, territorial e tecnológica do trabalho nos mais diferentes aspectos. Todos eles são proporcionais às escalas de produção e de demanda de serviços.

Ao dependerem da fluidez dos espaços, os fluxos estão diretamente vinculados à presença e eficiência dos sistemas técnicos, sistemas de engenharia e das infraestruturas, que dinamizam os deslocamentos. Assim, teoriza-se que quanto maior o número e a tecnologia das vias, dos terminais e dos veículos, mais dinamicamente se apresentam os fluxos.

Vale afirmar que a demanda turística se desloca pelos fluxos aéreo, terrestre, fluvial e marinho. Tais fluxos são responsáveis pela materialidade dessa demanda pelo território. A partir de seu mapeamento, esses fluxos podem contribuir de forma significativa para o estudo das conexões, nas mais diferentes escalas geográficas. 
Cruz (2001) afirma que essa definição faz generalizações quanto ao fluxo de turistas, pois a base dos dados está nos embarques e nos desembarques dos terminais e não no indivíduo. Contudo, é possível verificar aumento considerável nos fluxos de passageiros. Isso representa um ponto de partida para que se possa compreender a lógica de circulação de pessoas e do capital, representados pelas indústrias ligadas aos transportes, como empresas que executam o referido tipo de serviço (e seus serviços atrelados), que demonstram crescimento importante no setor aeronáutico, de carrocerias e de chassis de ônibus e, o mais importante, no nosso entendimento, o surgimento de novas companhias aéreas.

A grande motivação para a utilização do transporte aéreo decorre da velocidade de deslocamento e da amplitude da rede que possibilita a ligação com diferentes localidades no território brasileiro. As inter-relações humanas e econômicas foram modificadas a partir do contexto atual da globalização e do meio técnico-científico-informacional em que vivemos. No caso do nosso País, Santos e Silveira (2001, p. 52-53) enfatizam que a:

\begin{abstract}
União entre a ciência e a técnica que, a partir dos anos 70, havia transformado o território brasileiro revigora-se com novos e portentosos recursos da informação, a partir do período da globalização e sob a égide do mercado. E o mercado, graças exatamente à ciência, à técnica e à informação, torna-se um mercado global. O território ganha novos conteúdos e impõe novos comportamentos, graças às enormes possibilidades da produção e, sobretudo, da circulação dos insumos, dos produtos, do dinheiro, das ideias e informações, das ordens e dos homens.
\end{abstract}

Essa dinâmica, que se efetiva pela globalização, amplia a relação entre os "espaços do mandar" e os "espaços do fazer". Os primeiros, ordenadores da produção, do movimento e do pensamento são responsáveis pela criação das necessidades, no caso aqui analisado, das necessidades de deslocamento em busca de novos atrativos turísticos; os segundos são responsáveis pela instrumentalização e devem atender de forma satisfatória à demanda gerada pelos primeiros.

Pode-se dizer que o nexo informacional instalado gera o nexo circulacional, criando-se o movimento, inclusive do próprio turismo, cujos polos receptores são mais difusos e podem apresentar-se menos poderosos que os polos emissores (SANTOS; SILVEIRA, 2001), geralmente localizados nas regiões concentradas.

Certamente, ao tempo em que há deslocamento de pessoas, de mercadorias, de informações, de serviços e de capital, as infraestruturas tendem a acompanhar para atender à crescente demanda desses deslocamentos. Como exemplos dessas infraestruturas, estão rodovias e aeroportos construídos ou revitalizados com o objetivo de aumentar o volume de passageiros atendidos, de cargas 
e de mala postal. Logo, com o efetivo funcionamento de seu aeroporto, Parnaíba tem condição de transformar-se em um portal de acesso a toda a região, prescindindo da utilização da capital do Estado como parada intermediária.

Atualmente a região possui malha rodoviária em bom estado de conservação, cujo acesso principal ocorre pela Rodovia BR 343, que liga Teresina a Luís Correia, e pela BR 402, que liga Parnaíba a Jijoca de Jericoacoara (CE) e Barreirinhas (MA). Por sua vez, as rodovias estaduais mais utilizadas para o acesso aos municípios que compõem o Polo Costa do Delta são PI 315, que liga Luís Correia a Cajueiro da Praia (57 km), e a PI 210, que liga Parnaíba a Ilha Grande (6 km). Essas duas rodovias estaduais estão em bom estado de conservação e possibilitam o acesso aos quatro municípios em reduzido tempo.

O litoral do Estado do Ceará é acessível pelas rodovias BR 402 e CE 202 a partir de Parnaíba, contrastando com a dificuldade de acesso com o litoral Maranhense. Essa dificuldade de melhor acesso rodoviário compromete a integração com os Lençóis Maranhenses, destino turístico complementar, e traz como consequência maior dificuldade de consolidação de um destino turístico mais ampliado.

Santos e Silveira (2001), quando se referem à necessidade de construção de modernas rodovias como resposta à trama dos sistemas de engenharia, afirmam que, se antes havia a preocupação de implantação de um sistema de objetos que assegurassem a produção e seu escoamento para o mercado externo, hoje são esses sistemas de engenharia que devem garantir primeiro a circulação fluida dos produtos, para que a partir disso seja possível a produção em escala comercial.

O Aeroporto Internacional de Parnaíba (Pref. Dr. João Silva Filho) tem seu terminal de passageiros inspirado na arquitetura modernista do Aeroporto Santos Dumont, no Rio de Janeiro. Sua pista de pouso e decolagem, com 2,5 mil metros de comprimento, é considerada a $4^{\text {a }}$ maior do Nordeste, segundo dados da Empresa Brasileira de Infraestrutura Aeroportuária/ INFRAERO (2018).

Pelos dados apontados pela INFRAERO (2018), o movimento anual de passageiros no Aeroporto Internacional de Parnaíba (Tabela 1), verifica-se crescente demanda por voos para a cidade de Parnaíba e região, a partir de 2014, quando da introdução dos voos regulares da empresa Azul Linhas Aéreas, mas logo se percebeu o declínio deste número, o que demonstra falta de capacidade da cidade em manter a demanda necessária. 
TABELA 1 - MOVIMENTO ANUAL DE PASSAGEIROS (EMBARCADOS E DESEMBARCADOS) AEROPORTO DE PARNAÍBA

\begin{tabular}{|c|c|c|c|c|c|c|}
\hline \multirow[b]{2}{*}{ ANO } & \multicolumn{2}{|c|}{ Voos Regulares } & \multicolumn{3}{|c|}{ Voos Não Regulares } & \multirow[b]{2}{*}{ TOTAL } \\
\hline & Doméstico & Internacional & Doméstico & Internacional & $\begin{array}{c}\text { Executiva } \\
\text { e Geral }\end{array}$ & \\
\hline 2009 & 0 & 0 & 858 & 0 & 1.188 & 2.046 \\
\hline 2010 & 0 & 0 & 954 & 0 & 1.665 & 2.619 \\
\hline 2011 & 0 & 0 & 727 & 0 & 1.672 & 2.399 \\
\hline 2012 & 0 & 0 & 676 & 0 & 2.155 & 2.831 \\
\hline 2013 & 0 & 0 & 561 & 0 & 2.361 & 2.922 \\
\hline 2014 & 14.350 & 0 & 1.191 & 0 & 3.220 & 18.761 \\
\hline 2015 & 13.307 & 0 & 2.026 & 0 & 2.643 & 17.976 \\
\hline 2016 & 4.576 & 0 & 3.729 & 0 & 2.256 & 10.561 \\
\hline 2017 & 8.429 & 0 & 1.343 & 0 & 2.867 & 12.639 \\
\hline 2018 & 7.622 & 0 & 974 & 0 & 2.844 & 11.440 \\
\hline
\end{tabular}

Merece destaque ainda o fato de que a crescente demanda por voos "não regulares", a partir desse mesmo ano (2014), pode representar a expansão do meio técnico-científico de maneira pontual, sem garantias a uma maior integração regional.

As políticas públicas nas cidades litorâneas refletem leituras diferenciadas das dinâmicas em curso no espaço da economia mundial. A globalização é aí pensada como realidade para permitir uma mudança de escala no comércio mundial, por meio da ação dos Estados em busca de sua inserção em um espaço de fluxos global (CASTELLS, 2001), que depende do desempenho das "portas de entrada", aonde transitam turistas, capital, informações e mercadorias.

Esses sistemas incidem em maior ou menor grau na articulação geral do território sobrepostos com os sistemas desenvolvidos com a expansão de outros setores econômicos, igualmente dependentes das relações territoriais em diferentes escalas, como é o caso do comércio e da indústria, sistemas que necessitam de nós articuladores tanto mais potentes quanto maiores forem os fluxos de turistas. O desafio de criar acessibilidade aos destinos e mobilidade às localidades mais isoladas, a preços e tempo acessíveis, tem equalizado com avanços técnicos que criam meios de transportes mais rápidos e eficientes, infraestrutura mais segura e sistemas de comercialização mais ágeis. 
Atualmente a "contração das distâncias", favorecida pelos últimos avanços técnicos no transporte aéreo - cada vez mais capaz de chegar a qualquer destino do planeta sem escalas engendra a formação de uma periferia global a ser utilizada como atrativo turístico não somente para o aproveitamento interno, mas também para sua inserção no espaço turístico internacional.

As novas territorializações do capital e sua reprodução geográfica são manifestações dos deslocamentos espaciais. O trade turístico representa a materialização dessas territorializações, mas têm o capital privado e o Estado papel fundamental na sua estruturação, principalmente este último, responsável pela implantação de infraestruturas e de políticas de incentivo à atividade, e o capital privado é utilizador delas.

\section{POTENCIALIDADES, NÍVEL DE USO E FATORES LIMITANTES}

No Turismo verifica-se a confrontação das ideais de diferentes grupos sociais: os turistas e o residente, por exemplo. Esse residente se constrói enquanto "estilo de vida" diferente dos que visitam o local como pessoas de fora (os turistas). Cabe destacar que os objetos espaciais se apresentam como reflexo das relações sociais, que torna o valor do espaço, de sua expressão qualitativa, quantitativa e diversificada de recursos naturais disponíveis, determinada porção do espaço.

Nesse espaço se desenvolve uma complexa rede de relações sociais que permite uma acumulação histórica de trabalhos em que se sobrepõem ciclos de produção geradores de permanente ciclo de criação e recriação de objetos sobre a superfície terrestre. O espaço reflete os processos naturais e os sociais, que coexistiram até o tempo presente, pois a organização e o sentido atribuído ao espaço são resultado da transformação e da experiência da sociedade.

As duas maiores cidades do litoral, Parnaíba e Luís Correia, apresentam 94,35\% e 44,51\%, respectivamente, de população considerada urbana (PNUD, 2013). Esse fato pode justificar-se pela formação histórica da maior cidade do litoral e sua expansão em direção às praias mais afastadas do núcleo urbano, que se tornaram mais utilizadas pela população local como segunda moradia e pelos turistas em busca de lazer.

Com esse afluxo da população sobre o litoral, surge um processo de ocupação em todas as praias. Isso representa grande desafio para o ordenamento territorial da região, na medida em que se faz necessário estabelecer um zoneamento de usos e ações que visem priorizar as zonas mais 
adequadas para os diferentes tipos de atividades turísticas e outras atividades denominadas urbanas, considerando a avaliação da fragilidade dos diferentes sistemas que compõem a região. Dantas (2009) afirma que essas cidades, depois de incorporadas aos fluxos voltados às zonas de praia, passariam a ter sua configuração de cidade litorânea-interiorana extremamente abalada.

Esse conjunto de assentamentos, sem desenho e imagem urbana estética comprometida, em razão da falta de normas de construção e urbanização, de um lado, pouco contribui para a valorização das paisagens e recursos naturais da região; e, de outro, consolida a preocupação com a conservação ambiental e com a valorização do patrimônio natural da região, com uma adequação à imagem do destino que se pretende promover, com exigência, então, de planejamento cuidadoso da ocupação em particular da zona da orla.

Deste modo, é nesse processo de assentamento urbano em grandes proporções nas cidades do litoral piauiense que são analisadas as condições econômicas apresentadas (e utilizadas) para o desenvolvimento da região. Embora a ocupação do litoral piauiense remonte ao início da colonização, a urbanização de seu território se configura em relação ao Turismo a partir do surgimento de uma nova estrutura, refletida pelas edificações de veraneio, o que passaria a constituir parcelas do território voltadas exclusivamente para a atividade turística.

Nessa perspectiva, após relatar a necessidade de infraestruturas físicas e sociais, Selva (2012) lembra de que elas podem surgir a partir de ações espontâneas ou induzidas, por políticas, programas, projetos e planos, sob o comando de ação do poder público. Pode-se citar, por exemplo, o fornecimento de energia elétrica em domicílios que ainda não contam com esse serviço fundamental, por favorecer o desenvolvimento socioeconômico dos moradores locais, em regra marcados pela presença de elevados índices de pobreza, e ainda por viabilizar o acesso a outros serviços, tais como educação, saúde e saneamento básico.

Dados do PNUD (2013) apontam para um crescimento da oferta de energia elétrica à população residente entre os anos de 1991-2010. Apesar disso, os dados não são capazes de demonstrar a qualidade do serviço oferecido pela Eletrobrás - Distribuição Piaú (atual Equatorial Piauí), empresa responsável pelo fornecimento e distribuição de energia elétrica no estado.

Em 2010 foram instalados três parques eólicos na Praia da Pedra do Sal (Parnaíba), fato que contribuiu para minimizar os problemas de geração e qualidade da energia elétrica do litoral, embora seja necessário avaliar alguns importantes aspectos quanto aos impactos ambientais, como a alteração 
da flora e fauna, colisão de aves com as pás e, ainda, a poluição sonora e alteração da paisagem natural (Figura 4).

\section{FIGURA 04 - AEROGERADORES CONTRASTAM NA PAISAGEM DA PRAIA DA PEDRA DO SAL EM PARNAÍBA}
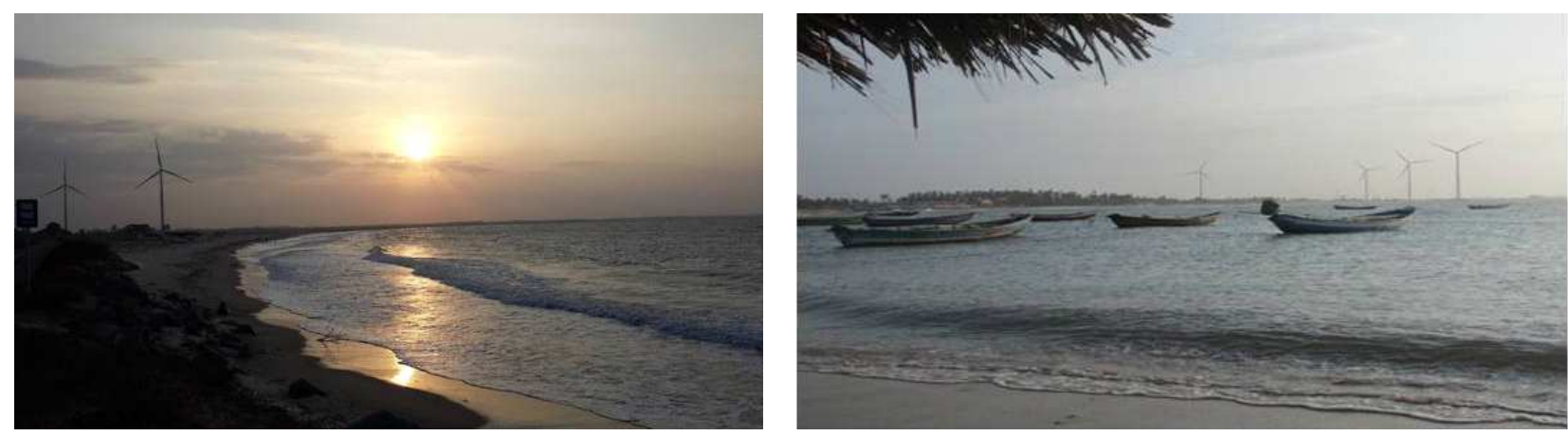

Fonte: Arquivo do autor (2019).

Outro componente importante para a melhoria das condições de vida da população é o saneamento básico na região, em especial nas áreas receptoras de turistas. A falta (ou precariedade) do saneamento básico constitui fator crítico do ponto de vista do impacto ambiental, que pode se acentuar com o aumento do fluxo de visitantes.

Em 2000, apenas 9,78\% da população em domicílios tinham acesso a banheiros e água encanada em Cajueiro da Praia. Isso demonstra debilidade que contraria o momento econômico vigente. Ressalte-se, contudo, que nesse mesmo município, em 2010, o montante vai a 29,69\%, o que representa um incremento de mais de três vezes os números referentes ao ano de 2000 . Inclusive Parnaíba, cidade mais importante do litoral, contabiliza apenas $81,17 \%$ de sua população com acesso a saneamento básico (acesso a banheiro e água encanada) (PNUD 2013).

Ainda, segundo dados do PNUD (2013), a existência de esgotamento sanitário inadequado atingia, em 2010, 49,72\% da população residente em Cajueiro da Praia e 26,27\% da população de Luís Correia.

Diante dessa realidade, se faz necessária a criação de projetos cujo objetivo maior seja capacitar a região com infraestrutura e serviços, para que seja possível, além da implantação de empreendimentos turísticos, a consolidação de um polo turístico.

Essa ação governamental pode trazer benefícios à população assentada ao longo do litoral com os serviços públicos destinados às necessidades sociais básicas. As carências sociais por serviços públicos sempre existiram e, a partir de agora, devem fazer parte da agenda governamental que volta seu interesse à possibilidade de instalação dos serviços turísticos na região. 
Ressalte-se que, com a implantação desses serviços, há uma elevação considerável do valor mercadológico da terra, o que termina por expulsar gradativamente as populações nativas. A política de Turismo pode ser considerada de ordem econômica e ao mesmo tempo influenciar diretamente nas questões sociais, forçando o poder público a desenvolver ações de cunho social, com a intenção de valorizar uma atividade produtiva que possa ser geradora de emprego e atinja o desenvolvimento regional. O poder público justifica os investimentos na implantação de infraestruturas necessárias ao Turismo por este corresponder a um dos potenciais de que o Estado dispõe par alcançar não somente o desenvolvimento do litoral, mas de grande parte de seu território.

O modelo de desenvolvimento econômico que vem sendo implantado, entretanto, promove a expulsão das populações nativas de seus locais de assentamento original, com a configuração da segregação social a partir da realocação espacial dos autóctones.

Com a ocupação de espaços menos nobres, geralmente localizados no entorno das aglomerações, localidades em que o valor da terra ainda não se elevou, essa população contribui para a expansão horizontal dos limites urbanos dos municípios e provoca a necessidade de expansão dos investimentos públicos em infraestruturas. Assim, na medida em que o valor da terra se eleva, o espaço construído se amplia e atinge áreas de uso potencial adequado à preservação e/ou conservação, que passa a ser degradado, por causa da implantação de estradas e outros fatores típicos da expansão urbana, como a necessidade de estações de tratamento de esgotos, por exemplo.

Nesse processo, as atividades que se encontram instaladas próximas ao núcleo em que estão implantados os equipamentos de prestação de serviços, servidos por infraestrutura, estariam à disposição para atender ao setor privado, que estaria apto a se apropriar da parte mais valorizada do espaço costeiro.

$\mathrm{O}$ acesso desigual aos meios de consumo coletivo está associado à maneira como as variadas classes sociais se relacionam com os valores de uso do solo, relação representada pela estratificação espacial e pela segregação social.

\section{CONCLUSÃO}

O Turismo acaba por acentuar problemas preexistentes, como a inserção diferencial dos moradores locais nas atividades turísticas da região, além de instaurar outros, até então inéditos em 
pequenas localidades do litoral nordestino, como a mobilidade da população local e seus efeitos mais profundos, entre os quais a periferização.

As reações favoráveis ou contrárias ao processo transformador, cujas origens estão nesses lugares afetados pelo Turismo, podem conter elementos das singularidades que caracterizam os diferentes pontos dispersos pelo litoral nordestino. Nesse sentido, é possível estar-se diante de uma multiplicidade de ações desenvolvidas em conformidade com o valor de uso ou com o valor de troca atribuído aos lugares. Esse fato pode ser constatado com a consolidação de um mercado imobiliário no litoral, o qual estimulou o turismo de segunda residência, aquele proveniente dos moradores da capital do Estado do Piauí.

O fenômeno se expandiu e atingiu de forma contundente a cidade de Luís Correia, em grande parte, pelo fato de apresentar as praias mais atrativas (Atalaia e Coqueiro) e, também, pela proximidade com a cidade de Parnaíba, que historicamente se fundamentou como aquela beneficiada com a maior parte da infraestrutura da região.

A valorização das áreas próximas às praias proporciona o surgimento de investimentos imobiliários voltados à atividade comercial e, também, à incorporação de condomínios residenciais que, associados à infraestrutura de serviços, introduzem uma nova prática de uso ao solo urbano.

Ainda se tratando da infraestrutura das cidades litorâneas, a precariedade dos investimentos na infraestrutura de transportes, nos serviços básicos e a carência de uma rede de estabelecimentos turísticos têm privado a região de maior desenvolvimento. O resultado desse processo é a criação de espaços turísticos que se concretizam, em grande parte, direcionados exclusivamente à prática da atividade econômica que garanta a inserção da população local, em grande medida, apenas como mão de obra explorada.

A despeito da precariedade das atividades desenvolvidas pelos indivíduos que optam pela estratégia de inserção no mercado turístico, quantidade expressiva de moradores dos municípios do litoral piauiense busca tal inserção. Essas práticas acabam por legitimar as transformações impetradas pelos agentes hegemônicos, em sua ação verticalmente constituída.

A capacidade de alterar o meio natural em curto prazo e de criar uma (re)produção socioespacial ligada à dinâmica da atividade turística implica nova valorização na sociedade local. Esta sociedade, por outro lado, em grande medida, ao se sentir excluída dos processos de benefícios extraídos dos equipamentos urbanos instalados para o desenvolvimento do turismo, passa a perceber na atividade uma questão meramente econômica. 
Cajueiro da Praia e Luís Correia são as cidades em que mais se percebe a compreensão do fenômeno turístico como panaceia para os problemas locais, percepção motivada pela maior dependência que as cidades têm em relação à referida atividade. Significa pensar e agir nos espaços turísticos para além das ações que oferecem a salvação pelo Turismo, incluindo-se aí questões sobre o turismo sustentável.

Por fim, como alternativa para o desenvolvimento dos espaços turísticos, deve-se buscar a conquista de melhores condições e qualidade de vida para uma população cada vez mais crescente. É na incorporação da qualidade de vida que uma sociedade complexa, diversa e desigual pode atingir níveis mais altos de desenvolvimento.

\section{REFERÊNCIAS}

BAPTISTA, E. M. de C. Estudo morfossedimentar dos recifes de arenito da zona litorânea do estado do Piauí, Brasil. 2010. 305 f. Tese (Doutorado em Geografia) - Programa de Pós-Graduação em Geografia, UFSC, Florianópolis-SC, 2010.

BOUÇAS DA SILVA, D. L.; RIBEIRO, R.T. Passado, presente e futuro: os desafios para o desenvolvimento turístico sustentável do Parque Nacional dos Lençóis Maranhenses. In: NASCIMENTO, E. P. \& COSTA. H. A. (Org.). Turismo e sustentabilidade: verso e reverso. Rio de Janeiro: Garamond, 2018. p. 25-49.

BRASIL. Ministério do Turismo. Índice de Competitividade do Turismo Nacional - 65 Destinos Indutores do Desenvolvimento Turístico Regional - Relatório Brasil 2011. Brasília-DF, 2012.

BRASIL. Ministério do Turismo. Plano Estratégico de Desenvolvimento do Turismo Regional da Rota das Emoções. São Paulo: 2014. Disponível em: http://www.turismo.gov.br/publicacoes/item/26-plano-estrategico-de-desenvolvimento-do-turismoregional-da-rota-das-emocoes.html. Acesso em: 23 ago. 2019.

BRASIL. Empresa Brasileira de Infraestrutura Aeroportuária. Anuário Estatístico Operacional de 2018. Brasília-DF: 2019. Disponível em: https://transparencia.infraero.gov.br/. Acesso em: 18 maio, 2020.

CARLOS, A. F. A. O espaço urbano: novos escritos sobre a cidade. São Paulo: Contexto, 2004.

CARLOS, A. F. A. O lugar no/do mundo. São Paulo: Labur, 2007.

CASTELlS, M. A sociedade em rede - (A era da informação: economia, sociedade e cultura, v. 1). 5. ed. São Paulo: Paz e Terra, 2001.

CRUZ, R. de C. A. da. Política de turismo e território. São Paulo: Contexto, 2000.

CRUZ, R. de C. A. da. Introdução à geografia do turismo. São Paulo: Roca, 2001. 
DANTAS, E. W. C. Maritimidade nos trópicos. Por uma Geografia do Litoral. Fortaleza: UFC, 2009.

INSTITUTO BRASILEIRO DE GEOGRAFIA E ESTATÍSTICA - IBGE. Censo Demográfico 2010. Disponível em: http://www.ibge.gov.br/cidadesat/index.php. Acesso em: 18 maio 2019.

INSTITUTO BRASILEIRO DE GEOGRAFIA E ESTATÍSTICA - IBGE. Cidades e Estados. Disponível em: http://www.ibge.gov.br/cidades-e-estados/. Acesso em: 18 maio 2020.

PERINOTTO, A.R.C. Investigando a Comunicação Turística de Parnaíba/PI - Brasil: internet e redes sociais, descrição e análise. Revista Turydes, v. 6 n.15, dez. 2013. Disponível em https://www.eumed.net/rev/turydes/index.htm. Acesso em: 12 maio 2020.

SANTOS, M. Pensando o espaço do homem. 4. ed. São Paulo: Hucitec, 1997.

SANTOS, M.; SILVEIRA, M. O Brasil: território e sociedade no início do século XXI. Rio de Janeiro: Record, 2001.

SANTOS, M. Metamorfoses do espaço habitado. 6. ed. São Paulo: EDUSP, 2012.

SERVIÇO DE APOIO ÀS MICRO E PEQUENAS EMPRESAS - PIAUÍ - SEBRAE/PI. Plano estratégico de desenvolvimento do turismo no Piauí - 2012 / 2020. Teresina: SEBRAE/PI, 2012.

SELVA, V. S. F. Uma abordagem acerca de políticas públicas e gestão municipal do turismo. In: CASTILHO, C. J. M. de. SELVA, V. S. F. Turismo, políticas públicas e gestão dos ambientes construídos. Recife: UFPE, 2012. p. 35-52.

SOUSA, P. G. E. A "mão invisível” sob a turistificação do espaço litorâneo nordestino. In: CASTILHO, Cláudio Jorge Moura de. SELVA, Vanice Santiago Fragoso. Turismo, políticas públicas e gestão dos ambientes construídos. Recife: UFPE, 2012. p. 141-154. 